\title{
Methodological aspects, dose-response characteristics and causes of interindividual variation in insulin stimulation of limb blood flow in normal subjects
}

\author{
T. Utriainen ${ }^{1}$, R.Malmström ${ }^{2}$, S. Mäkimattila ${ }^{2}$, H. Yki-Järvinen ${ }^{2}$ \\ ${ }^{1}$ Second Department of Medicine, Helsinki University Central Hospital, Helsinki, Finland \\ ${ }^{2}$ Third Department of Medicine, Helsinki University Central Hospital, Helsinki, Finland
}

\begin{abstract}
Summary To resolve some of the controversy regarding insulin regulation of blood flow, we performed in 20 normal subjects a) a reproducibility study of plethysmographic, Doppler ultrasound and laser Doppler blood flow measurements $(n=7)$, b) a sequential insulin dose-response study with measurement of forearm (plethysmography), leg (Doppler ultrasound) and skin (laser Doppler) blood flow $(n=12)$, and c) a sequential insulin dose-response study with comparison of forearm (plethysmography) and calf (plethysmography) blood flow $(n=8)$. We also searched for factors which might explain the interindividual variation in the blood flow response to insulin. During sequential insulin infusions $(2 \mathrm{~h}$ each, $61 \pm 2,139 \pm 6,462 \pm 15 \mathrm{mU} / 1)$, forearm blood flow increased by $17 \pm 6,50 \pm 14$ and $113 \pm 17 \%$ ( $p<0.05$ or less between steps), respectively. The increase at the $61 \pm 2 \mathrm{mU} / \mathrm{l}$ insulin concentration barely exceeded methodological variation $(13 \pm 2 \%)$. In contrast to the continuous increase in blood flow, the glucose arterio venous difference reached its maximum $(1.7 \pm 0.2 \mathrm{mmol} / \mathrm{l})$ at the lowest $61 \pm 2 \mathrm{mU} / 1$ insulin concentration and remained constant thereafter. Forearm and calf blood flow responses to insulin were virtually identical when determined with ple-
\end{abstract}

thysmography. In contrast, only a $27 \%$ increase was detected in femoral flow index as determined by Doppler ultrasound. Forearm blood flow (per forearm volume) was highly correlated with the relative forearm muscle content (mean $59 \pm 5 \%$, range $24-81 \%$ ) both basally ( $r=0.86, p<0.001, n=12)$ and at all insulin concentrations $(r=0.85-0.92, p<0.001)$ indicating that the percent of forearm that is muscle explains $70-85 \%$ of interindividual variation in blood flow. In conclusion 1) physiological insulin concentrations stimulate glucose uptake mainly by increasing glucose extraction while supraphysiological insulin concentrations increase forearm glucose uptake predominantly via increases in blood flow. 2) The dose-response characteristics of insulin stimulation of forearm and calf blood flow are similar when determined with strain-gauge plethysmography. 3) Relative forearm muscle content is a key factor in determining both basal forearm blood flow and the interindividual variation in its response to insulin in normal subjects. [Diabetologia (1995) 38: 555-564]

Key words Hyperinsulinaemic clamp, muscle, blood flow, venous occlusion plethysmography, Doppler ultrasound, blood pressure.
Across a limb, the glucose arteriovenous difference and blood flow provide measures of glucose extraction and delivery, respectively [1]. Using the thermo-

Received: 20 January 1994 and in revised form 2 September 1994

Corresponding author: Dr. H. Yki-Järvinen, Third Department of Medicine, Helsinki University Central Hospital, Haartmaninkatu 4, FIN-00290 Helsinki, Finland. dilution technique to measure leg blood flow, Laakso et al. [2] and Baron et al. [3] have demonstrated that insulin induces a variety of haemodynamic responses in normal subjects and that deficiency of such responses to insulin characterizes several insulin-resistant states $[2,4,5]$.

In contrast to the marked $[2,3,6,7]$ increases in blood flow in the studies performed using the thermodilution technique, no increase [8-14] or a less marked increase [15-19] in the blood flow response 
to insulin has been found in other studies. Several factors, especially duration and dose of insulin infusion, as well as location and technique used for measurement of blood flow, could contribute to these apparently contradictory results. In most $[8,11,13,14]$ although not all $[9,17]$ studies performed across the forearm, the insulin concentration has been in the high physiological rather than the supraphysiological range and insulin has been infused on separate days rather than sequentially. In separate infusion studies where the insulin concentration has been supraphysiological, Gallen and MacDonald [19] found a $44 \%$ increase in forearm blood flow within $1.5 \mathrm{~h}$ at an insulin concentration of $240 \mathrm{mU} / 1$, Bonadonna et al. [17] found a significant $25 \%$ increase within $2 \mathrm{~h}$ at an insulin concentration of $1600 \mathrm{mU} / \mathrm{l}$ while YkiJärvinen et al. [9] found a non-significant $15 \%$ increase within $2 \mathrm{~h}$ in normal volunteers at an insulin concentration of $1700 \mathrm{mU} / \mathrm{l}$. Similarly, Capaldo et al. [12] found no significant change in forearm blood flow in $2 \mathrm{~h}$. These increases in flow are clearly less than those reported in studies using sequential supraphysiological insulin infusions. Laakso et al. [2] found a $60-70 \%$ increase in flow within $9 \mathrm{~h}$, Dela et al. [20] a $65-79 \%$ increase within $6 \mathrm{~h}$ and Richter et al. [21] a $40-51 \%$ increase within $5.5 \mathrm{~h}$, the highest insulin infusion rates being 15 [2], 12 [20] and $5 \mathrm{mU} / \mathrm{kg} \cdot \mathrm{min}$ [21], respectively. All of these three studies were performed across the leg rather than the forearm.

It is unclear at present whether these differences in the blood flow response to insulin are due to the differences in the duration of the studies or to inherent differences between the response of forearm and leg tissues to insulin. Also, methodological factors may be important as the thermodilution technique was used in the studies across the leg $[2,20,21]$ and plethysmography or dye dilution across the forearm [9$14,16,17,19]$.

Another unresolved issue regarding insulin stimulation of blood flow is why the response is highly variable between individuals [3]. At the level of the whole body, insulin sensitivity is positively correlated with the percent of body weight which is muscle [22]. It is, however, unknown whether individual characteristics such as forearm composition could explain some of the considerable interindividual variation in the blood flow response to insulin.

For both technical and ethical reasons, use of invasive thermal or dye dilution techniques necessitating arterial catheterization are not suitable for studying large groups of individuals. There is therefore a need to resolve some of the controversies discussed above. To answer these questions we first determined the reproducibility of blood flow measurements using mercury-in-rubber strain-gauge plethysmography and Doppler ultrasound. We thereafter performed identical sequential dose-response studies in two matched groups of volunteers. In both groups, forearm blood flow was measured using strain-gauge plethysmography. In the other group this measurement was combined with measurement of femoral blood flow using Doppler ultrasound and skin blood flow using laser Doppler flowmetry. In the other group, measurement of forearm glucose uptake was combined with measurement of calf blood flow with plethysmography.

\section{Subjects and methods}

Subjects. The studies comprised 20 young adult normotensive volunteer subjects, 10 women and 10 men. The volunteers were healthy as judged by medical history and physical examination and were not taking any drugs known to affect glucose metabolism. Their age was $24 \pm 1$ years (mean \pm SEM), weight $70.1 \pm 3.7 \mathrm{~kg}$, height $177 \pm 3 \mathrm{~cm}$, and body mass index $22.2 \pm$ $0.7 \mathrm{~kg} / \mathrm{m}^{2}$. Their fasting plasma glucose $(5.1 \pm 0.1 \mathrm{mmol} / \mathrm{l})$, serum insulin $(6 \pm 1 \mathrm{mU} / 1)$ and glycated haemoglobin $\left(\mathrm{HbA}_{1 \mathrm{c}}\right.$, $4.9 \pm 0.1 \%$, reference range $4-6 \%$ ) concentrations were in the normal range. The subgroups of subjects that participated in the reproducibility study and the two insulin dose-response studies were matched for age, gender and BMI (data not shown). For 2 days before the studies, the subjects consumed a weight-maintaining diet containing at least $200 \mathrm{~g}$ of carbohydrate per day. Informed consent was obtained after the purpose, nature and potential risks were explained to the subjects. The experimental protocol was approved by the ethical committee of the Helsinki University Central Hospital.

\section{Study protocols}

Reproducibility study. To evaluate the reproducibility of the blood flow (plethysmography, Doppler ultrasound, laser Doppler) measurements, and to exclude non-specific or diurnal changes in haemodynamic parameters, seven of the volunteers participated in a 7 -h reproducibility study. The study was performed after a 10-12 h overnight fast at 07.30 hours. Hypotonic saline was infused in the left antecubital vein at a rate of at least $140 \mathrm{ml} / \mathrm{h}$ during the $7-\mathrm{h}$ study to match for the volume infused during the clamp. Blood pressure, heart rate, forearm blood flow, blood flow velocity in the femoral artery, skin circulation and surface temperature were measured hourly as described below.

Sequential insulin dose-response study with measurement of forearm glucose uptake and blood flow (plethysmography), leg blood flow (Doppler ultrasound) and skin (laser Doppler) blood flow. Twelve subjects participated in a sequential 7 -h insulin clamp study with insulin infusion rates of 0 (basal, $1 \mathrm{~h}), 1$ (step I), 2 (step II) and $5 \mathrm{mU} / \mathrm{kg} \cdot \mathrm{min}$ (step III) ( 2 h each). During the clamp, whole body and forearm glucose uptake and haemodynamic parameters (heart rate, blood pressure) were measured. Forearm blood flow was measured using straingauge plethysmography as detailed later in this paper. In addition, leg blood flow velocity and skin blood flow were determined using Doppler ultrasound and laser Doppler flowmetry, respectively.

Sequential insulin dose-response study with measurement of forearm glucose uptake and blood flow (plethysmography) and calf blood flow (plethysmography). A similar hyperinsulinaemic sequential dose-response clamp protocol as de- 
scribed was used in another group of normal subjects $(n=8)$. Forearm and calf blood flow were measured simultaneously using strain-gauge plethysmography as described in detail later in this paper.

\section{Methods}

Sequential dose-response insulin clamp study. The study was started after a $10-12 \mathrm{~h}$ fast at 07.30 hours. Before the hyperinsulinaemic clamp the subjects ingested $2 \mathrm{~g}$ potassium chloride in a sustained release formulation (Durekal; Leiras, Tur$\mathrm{ku}$, Finland) to counteract hypokalaemia, and three 18 gauge catheters (Venflon; Viggo-Spectramed, Helsingborg, Sweden) were inserted as previously described [9]. Insulin and glucose were infused in a catheter inserted in the left antecubital vein. The left hand was kept in a heated chamber $\left(65^{\circ} \mathrm{C}\right)$ and arterialized venous blood was withdrawn from a heated dorsal hand vein. The deep branch of the right medial cubital vein draining forearm muscles was cannulated retrogradely so that the tip of the cannula could not be palpated superficially.

The euglycaemic hyperinsulinaemic clamp was used to assess tissue sensitivity to insulin as previously described [23]. At each step insulin (Actrapid Human; Novo Nordisk, Copenhagen, Denmark) was infused in a primed continuous manner at rates of $1(60-180 \mathrm{~min}), 2(180-300 \mathrm{~min})$ and $5(300-$ $420 \mathrm{~min}$ ) $\mathrm{mU} / \mathrm{kg} \cdot \mathrm{min}$. Normoglycaemia was maintained by adjusting the rate of a $20 \%$ glucose infusion based on plasma glucose measurements performed at 5-min intervals. As hepatic glucose output has been shown repeatedly to be completely suppressed in normal volunteers even under isotopic steadystate conditions at the insulin concentrations employed in the present study [9,24-26], whole body glucose uptake was calculated from the glucose infusion rate after correcting for changes in the glucose pool size [23].

Forearm glucose uptake and measurement of forearm blood flow using strain-gauge plethysmography. Forearm glucose uptake was calculated by multiplying the glucose arteriovenous difference by forearm blood flow [1]. Plasma glucose values were converted to whole blood values by multiplying plasma glucose concentrations with $1-(0.30 \times$ haematocrit $)$ [27]. Forearm blood flow was measured every $30 \mathrm{~min}$ with venous occlusion plethysmography [28] using a mercury in silastic rubber strain-gauge apparatus (Hokanson Plethysmograph Model EC-4; Issaquah, Washington, USA). The gauge was attached around the widest, most muscular [9] segment of the forearm. Two minutes before blood sampling and flow measurements the circulation to the hand was interrupted by inflating a paediatric blood pressure cuff around the wrist to above the systolic blood pressure. Venous return was then occluded by rapidly inflating a sphygmomanometer cuff around the upper arm to $50 \mathrm{~mm} \mathrm{Hg}$. Several acceptable curves were recorded (OmniScribe recorder; Houston Instrument, Gistel, Belgium). In this study arterial inflow was determined by drawing a tangential line for the first few pulses following cuff inflation. The slope of that line reflects the volume change per unit time.

The method of calibration of a venous occlusion plethysmograph may significantly influence the results. Calibration can be performed using the built-in calibration signal for a $1 \%$ volume change, the height of which is used for blood flow calculations (slope method). A direct method for calibration has previously been described by Yki-Järvinen et al. [11]. After venous occlusion, blood is withdrawn into a syringe attached to the deep forearm vein catheter at a speed preventing any further change in voltage as shown in Figure 1 (withdrawal method). Thus, the rate of blood withdrawal will equal the arterial

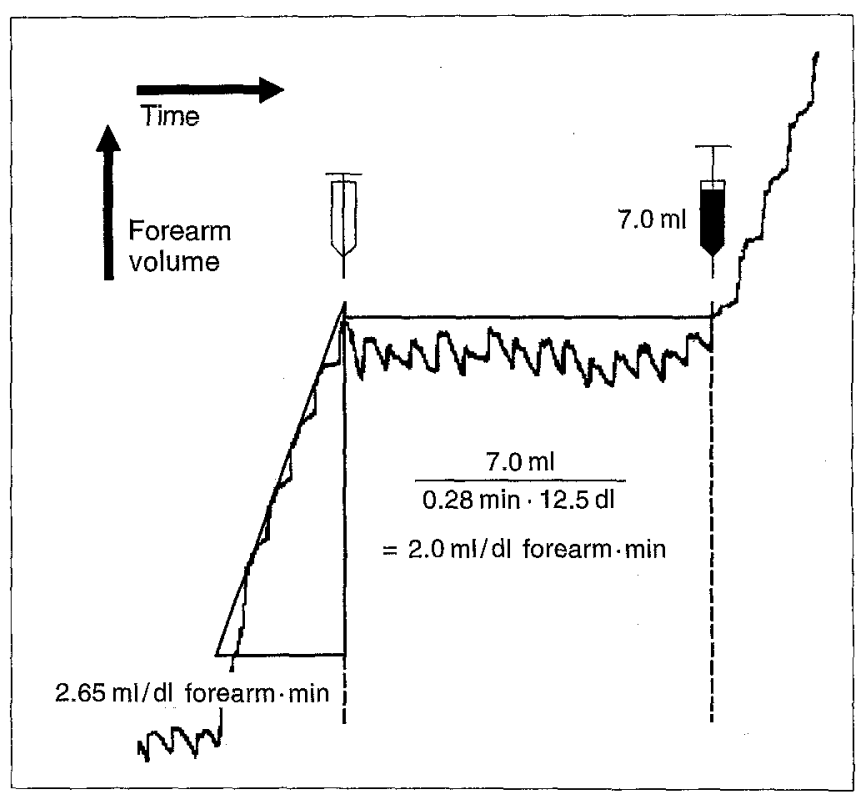

Fig. 1. Two methods for measuring forearm blood flow using venous occlusion plethysmography. In the slope method, the slope of the line characterizing the increase in volume induced by venous occlusion can be used to obtain flow rate from a known calibration signal and chart speed. In the example shown in the figure, this rate is $2.65 \mathrm{ml} / \mathrm{dl}$ forearm $\mathrm{min}$. This flow rate reflects flow in the segment underlying the strain gauge. Alternatively, one may use the withdrawal method to determine blood flow in all of the forearm. When this method is used, blood is withdrawn from a forearm vein to a syringe at a rate which prevents any further change in forearm volume. The arterial inflow rate can then be calculated by dividing the blood volume in the syringe by time and forearm volume, which is measured by water displacement

inflow rate at least in the segment circumscribed by the gauge. To determine whether the slope and withdrawal methods of calibration give identical results we compared data from 16 subjects, nine of which are reported here, in whom forearm blood flow was calculated using both methods simultaneously. In an analysis of 204 blood flow measurements, the correlation coefficient between flow rates obtained with the two methods was $r=0.92(p<0.001)$. However, the results were not identical as the withdrawal method on average gave $19 \pm 4 \%$ lower blood flow rates than the slope method.

Measurement of calf blood flow using strain-gauge plethysmography. Calf blood flow was measured at 30-min intervals $10 \mathrm{~min}$ before the measurement of forearm blood flow. The apparatus used was similar to that described above. Before the measurement circulation to the foot was interrupted using a blood pressure cuff inflated to suprasystolic pressure around the ankle and the leg was elevated slightly above heart level. The gauge was placed around the widest segment of calf and the venous occlusion cuff just proximal to the knee. Several arterial inflow curves were recorded after the venous occlusion cuff was rapidly inflated to a individually predetermined pressure to produce maximal arterial inflow rates.

Measurement of flow velocity in the femoral artery by Doppler ultrasound. For non-invasive estimation of blood flow velocity in the femoral artery, a Doppler ultrasound velocimeter (U1trasound Scanner Model EUB-565; Hitachi Medical Corpora- 

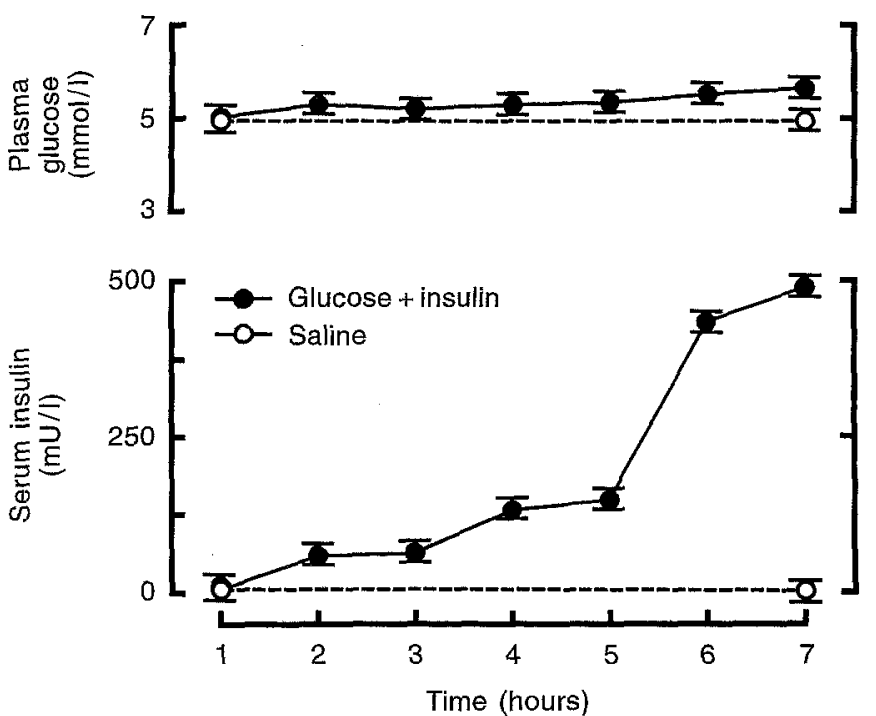

Fig. 2. Plasma glucose and serum insulin concentrations during the clamp

tion, Tokyo, Japan) with a steerable continuous wave Doppler probe (EUB-SD522, $5 \mathrm{MHz}$ ) was used. Using the B-mode real time image the right common femoral artery was visualized distally to the inguinal ligament and proximally to the deep branch of the femoral artery. The angle of approach of the Doppler beam, ranging 51-63 degrees, was determined with a simultaneous B/Pulsed-wave Doppler mode when the femoral artery was visualized along its long axis. The sample volume was then electronically placed within the lumen approximately $2 \mathrm{~cm}$ proximal to the deep branch of the femoral artery. With a sample volume length ranging $7-12 \mathrm{~mm}$ most of the lumen could be uniformly insonificated in each subject. We did not attempt to calculate total blood flow since estimation of the vessel diameter may be inaccurate with this method. Instead we used the systolic peak blood flow velocity as an indicator of blood flow changes. First, it has earlier been shown that peak flow velocity is well correlated with time-averaged flow velocity (Berne, personal communication). Second, the waveform tracing capabilities in the equipment were not satisfactory for mean flow velocity calculations. Third, subjectively, the shape of the Doppler waveform remained constant during the study. A flow index was therefore developed to estimate volume flow. It was calculated by multiplying the peak flow velocity by heart rate and expressed in arbitrary units. The theoretical basis of the Doppler ultrasound method for blood flow measurements has been reviewed in detail previously [29].

Laser Doppler flowmetry. Microvascular perfusion of the skin was measured by laser Doppler flowmetry (PeriFlux PF3 Laser Doppler Perfusion Monitor; Perimed, Järfälla, Sweden) with a standard probe (PF 308). The probe holder was attached on the anterior surface of the thigh over the quadriceps muscle group. The perfusion unit reading was monitored every $30 \mathrm{~min}$ for $1 \mathrm{~min}$ and the lowest value was recorded. To exclude the potential effect of temperature changes of the skin on skin perfusion we monitored the surface temperature near the laser Doppler probe using an electronic thermometer (Delta Thermometer; Padova, Italy).

Forearm muscle content. By analysing sequential cross-sectional computerised tomography (CT) scans of the forearm Maughan et al. [30] developed equations which allow prediction of forearm fat and muscle volume on the basis of biceps skinfold thickness. We used Harpenden callipers (John Bull, British Indicators Ltd, UK) to measure the biceps skinfold thickness, and water displacement to measure total forearm volume. Relative forearm muscle content was calculated by dividing forearm muscle volume by total forearm volume.

Heart rate and blood pressure. Heart rate, systolic and diastolic blood pressures were measured every $30 \mathrm{~min}$. Pulse pressure was calculated from the difference between systolic and diastolic blood pressures and mean arterial pressure by adding one third of the pulse pressure to the diastolic blood pressure.

Analytical methods. Plasma glucose concentrations were measured in duplicate using the glucose oxidase method [31], with the Beckman Glucose Analyzer II (Beckman Instruments, Fullerton, Calif., USA). Serum free insulin was determined every $30 \mathrm{~min}$ by double antibody radioimmunoassay (Pharmacia Insulin RIA kit; Pharmacia, Uppsala, Sweden) after precipitation with polyethylene glycol [32].

\section{Statistical analysis}

The dose-response curves were analysed by analysis of variance (ANOVA) for repeated measures followed by the Student's $t$-test. All calculations were made using the SYSTAT statistical package (SYSTAT Inc., Evanston, Ill., USA). The results are expressed as means \pm SEM. $P$-values less than 0.05 were considered to be statistically significant.

\section{Results}

Reproducibility study. During the saline infusion, plasma glucose remained at its fasting concentration while serum insulin fell slightly from $5 \pm 1$ to $3 \pm$ $1 \mathrm{mU} / \mathrm{l}(p<0.05)$ during the 7-h study (Fig. 2$)$. Forearm blood flow averaged $2.2 \pm 0.1(0-1 \mathrm{~h}), 2.3 \pm 0.1$ $(2-3 \mathrm{~h}), 2.4 \pm 0.1(4-5 \mathrm{~h})$ and $2.6 \pm 0.2 \mathrm{ml} / \mathrm{dl}$ forearm per min $(6-7 \mathrm{~h})$ with no significant change over time (Fig. 3). The coefficient of variation (CV) of the hourly forearm blood flow measurements during the 7-h study was $13 \pm 2 \%$, and of skin perfusion measurements $50 \pm 3 \%$. Across the femoral artery, systolic peak blood flow velocity averaged $74 \pm 5(0-1 \mathrm{~h})$, $71 \pm 5(2-3 \mathrm{~h}), 72 \pm 5(4-5 \mathrm{~h})$ and $74 \pm 5 \mathrm{~cm} / \mathrm{s}(6-7 \mathrm{~h})$ with no significant change over time (Fig. 4). The CV of the hourly peak flow velocity measurements during 7 -h study was $4 \pm 1 \%$. No significant trends in heart rate, systolic or diastolic blood pressures, pulse pressure and mean arterial pressure were observed.

\section{Sequential insulin dose-response study with measurement of forearm glucose uptake and blood flow (plethysmography), leg blood flow (Doppler ultrasound) and skin (laser Doppler) blood flow}

Glucose and insulin concentrations, whole body glucose utilization. Normoglycaemia was maintained throughout the study (Fig.2). Serum insulin concen- 

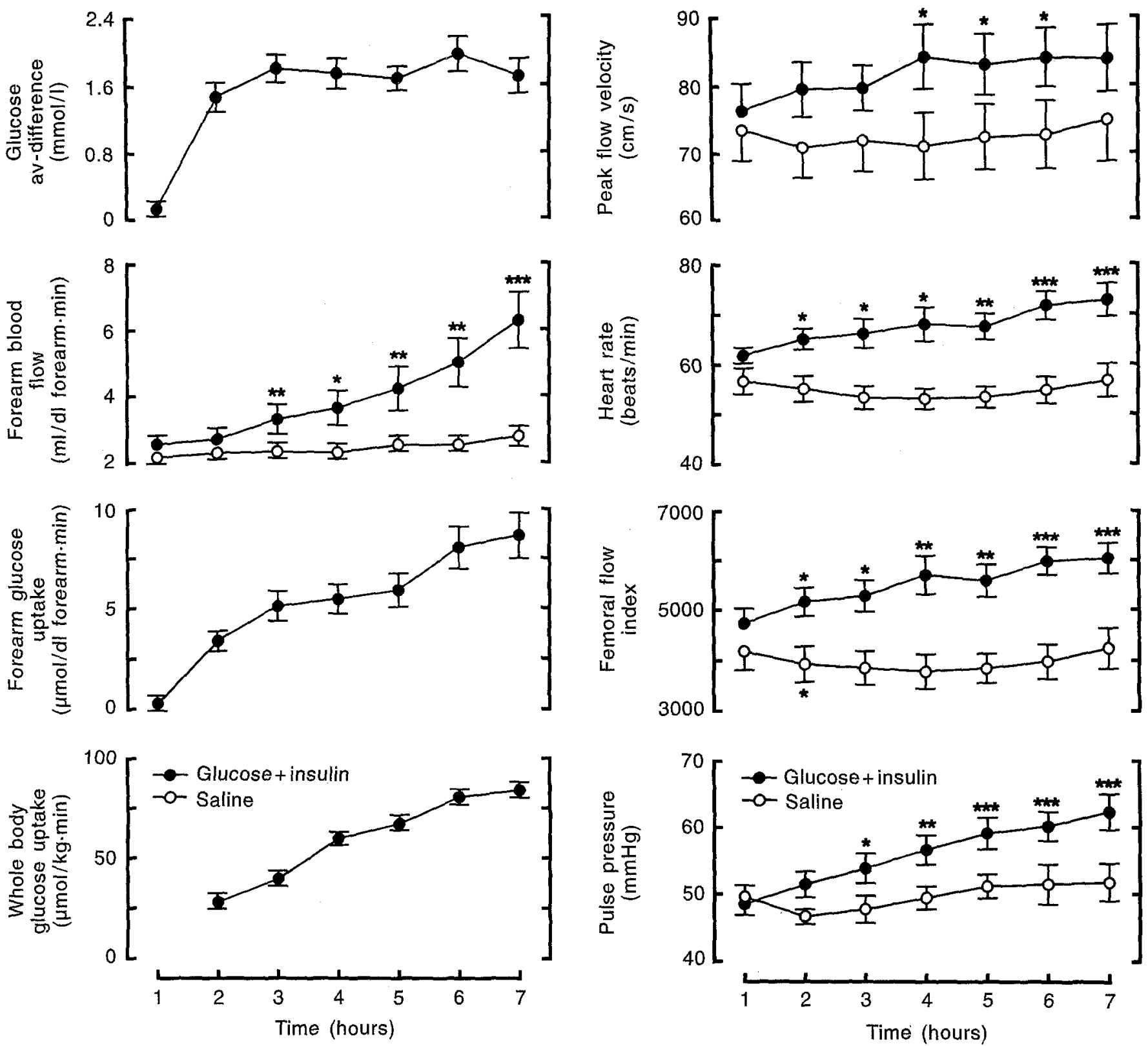

Fig. 3. The arteriovenous difference for glucose, forearm blood flow, calculated forearm, and whole body glucose uptake. $* p<0.05, * * p<0.01$ and **** $p<0.001$ vs $0-1 \mathrm{~h}$ (basal period)

trations averaged $6 \pm 1$ (basal), $61 \pm 2$ (step I), $139 \pm 6$ (step II) and $462 \pm 15 \mathrm{mU} / \mathrm{l}$ (step III). Whole body glucose utilization rose dose-dependently and averaged $33.9 \pm 2.2$ (step I), $63.5 \pm 3.0$ (step II, $p<0.001$ vs step I) and $82.2 \pm 3.4 \mu \mathrm{mol} / \mathrm{kg} \cdot \mathrm{min}$ (step III, $p<0.001$ vs steps I and II).

Forearm glucose uptake. The glucose arteriovenous difference increased from $0.13 \pm 0.01$ to $1.65 \pm$ $0.16 \mathrm{mmol} / 1(p<0.001)$ in response to the lowest insulin concentration but remained constant thereafter $(1.72 \pm 0.15$ and $1.83 \pm 0.20 \mathrm{mmol} / \mathrm{l}$ for steps II and III, both NS vs step I, Fig.3). In contrast, forearm

Fig.4. Peak flow velocity in the femoral artery, heart rate, femoral flow index calculated by multiplying peak flow velocity with heart rate and pulse pressure during the clamp (- - ) and in the reproducibility study $(-O-)$. Statistically significant differences from the baseline $(0-1 \mathrm{~h})$ are depicted: $* p<0.05$, $* * p<0.01$ and $* * * * 0.001$

blood flow increased continuously and averaged $2.6 \pm 0.3$ (basal), $3.0 \pm 0.4$ (step I, $p<0.05$ vs basal), $3.9 \pm 0.6$ (step II, $p<0.01$ vs basal and step I), $5.6 \pm$ $0.8 \mathrm{ml} / \mathrm{dl}$ forearm $\cdot \min$ (step III, $p<0.001$ vs each previous step). Forearm blood flow increased in a dosedependent manner (Fig. 3) and the percent increases vs baseline value were $17 \pm 6 \%$ (range -12 to $60 \%$ ), $50 \pm 14 \%$ ( 3 to $153 \%$ ) and $113 \pm 17 \%$ (42 to $248 \%$ ) for steps I, II and III, respectively. Forearm blood flow was significantly $(p<0.01)$ higher than at baseline from $180 \mathrm{~min}$ (end of step I) onwards. Forearm 
Table 1. Heart rate, systolic, diastolic blood pressures, pulse pressure and mean arterial pressure during the clamp study

\begin{tabular}{|c|c|c|c|c|}
\hline & Basal & Step I & Step II & Step III \\
\hline Heart rate (beats/min) & $62 \pm 2$ & $66 \pm 2^{b}$ & $68 \pm 3^{b}$ & $72 \pm 3^{\mathfrak{c}}$ \\
\hline Systolic blood pressure $(\mathrm{mm} \mathrm{Hg})$ & $116 \pm 2$ & $116 \pm 2$ & $119 \pm 3$ & $120 \pm 3^{\mathrm{a}}$ \\
\hline Diastolic blood pressure $(\mathrm{mm} \mathrm{Hg}$ ) & $68 \pm 2$ & $64 \pm 2^{b}$ & $63 \pm 2^{b}$ & $60 \pm 2^{c}$ \\
\hline Pulse pressure $(\mathrm{mm} \mathrm{Hg})$ & $48 \pm 2$ & $53 \pm 2$ & $58 \pm 2^{c}$ & $62 \pm 2^{c}$ \\
\hline Mean arterial pressure $(\mathrm{mm} \mathrm{Hg})$ & $84 \pm 2$ & $81 \pm 2^{b}$ & $82 \pm 2$ & $81 \pm 2^{a}$ \\
\hline
\end{tabular}

${ }^{\mathrm{a}} p<0.05,{ }^{\mathrm{b}} p<0.01,{ }^{\mathrm{c}} p<0.001$ vs basal

glucose uptake averaged $4.3 \pm 0.6$ (step I), $5.7 \pm 0.7$ (step II, $p<0.05$ vs step I) and $8.3 \pm 1.1 \mu \mathrm{mol} / \mathrm{dl}$ forearm.min (step III, $p<0.001$ vs steps I and II, Fig.3).

Leg blood flow velocity. The femoral systolic peak flow velocity averaged $76 \pm 4$ (basal), $79 \pm 4$ (step I, NS vs basal), $84 \pm 5$ (step II, $p<0.05$ vs basal and step I) and $84 \pm 4 \mathrm{~cm} / \mathrm{s}$ (step III, $p<0.05 \mathrm{vs}$ basal). The femoral flow index (peak flow velocity multiplied by heart rate) increased $27 \%$ during $7 \mathrm{~h}$ (Fig.4). Average values were $4742 \pm 298$ (basal), $5226 \pm 287$ (step I, $p<0.05$ vs basal), $5643 \pm 356$ (step II, $p<0.001$ vs basal, $p<0.05$ vs step I) and $6000 \pm 284$ (step III, $p<0.001$ vs basal and step I).

Haemodynamic parameters. (Table 1) During the 6-h clamp, heart rate increased by $18 \%$ from $62 \pm 2$ (basal) to $72 \pm 3$ beats per min (step III, $p<0.001$ vs basal). A minor increase in systolic blood pressure was observed. Diastolic blood pressure fell $13 \%$ between 0 and $7 \mathrm{~h}$. Pulse pressure increased significantly during the insulin infusions (Fig.4). The percent increase in pulse pressure between 0 and $7 \mathrm{~h}$ was $28 \%$. Mean arterial pressure decreased slightly over time.

Skin blood flow. Skin perfusion did not change significantly during the studies. In the clamp study skin blood flow averaged $2.2 \pm 0.6,3.4 \pm 0.8,3.5 \pm 0.6$ and $2.3 \pm 0.6$ perfusion units at baseline and steps I, II and III, respectively. In the reproducibility study averages were $2.2 \pm 0.4(0-1 \mathrm{~h}), 2.4 \pm 0.6(2-3 \mathrm{~h}), 1.2 \pm$ $0.2(4-5 \mathrm{~h})$ and $1.2 \pm 0.4$ perfusion units $(6-7 \mathrm{~h})$. Skin temperature averaged $32.2 \pm 0.3$ (basal), $32.7 \pm 0.5$ (step I), $32.9 \pm 0.4$ (step II) and $33.0 \pm 0.4$ (step III) with no significant change over time. No significant changes were detected in the reproducibility study.

Forearm muscle composition. The relative forearm muscle content averaged $59 \pm 5 \%$ (range $24-81 \%$ ). Forearm blood flow, expressed per unit volume of forearm, was highly correlated with the percent muscle in forearm both basally $(r=0.86, p<0.001)$ and during the clamp at all insulin concentrations (step I $r=0.92 ;$ step II $r=0.85$; step III $r=0.87, p<0.001$ for each) (Fig.5). To determine whether insulin increased blood flow more in individuals with a high as compared to a low percent muscle in forearm, we analysed whether the slopes of the linear regression

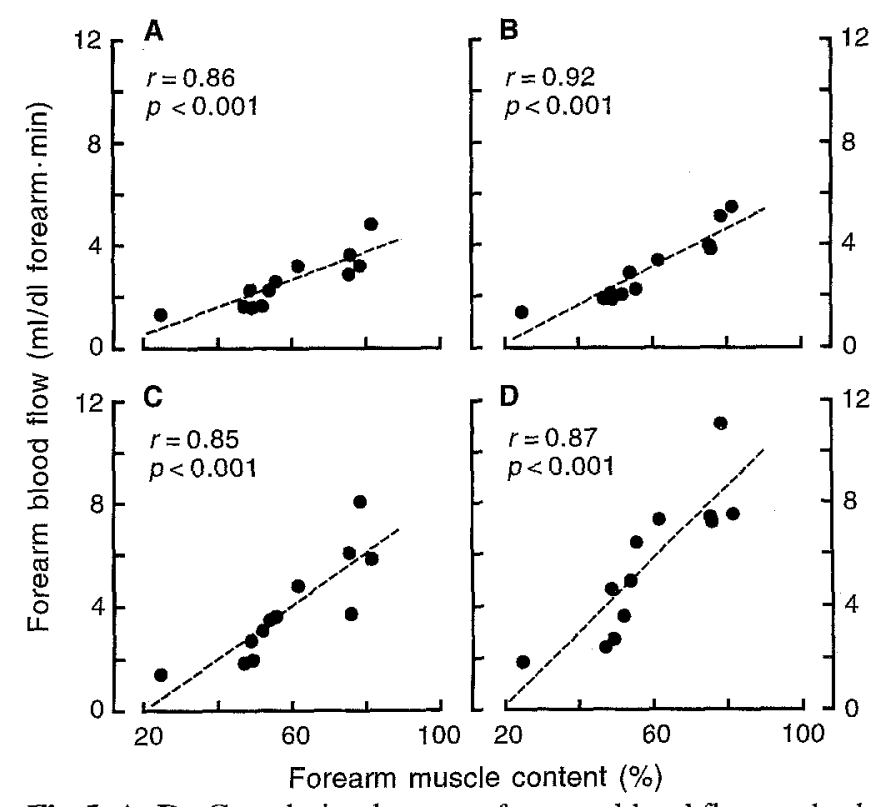

Fig. 5. A-D. Correlation between forearm blood flow and relative forearm muscle content (\% muscle in forearm) in the 12 subjects in the basal state $(\mathbf{A})$, and during the 1 (B), 2 (C) and 5 (D) $\mathrm{mU} / \mathrm{kg} \cdot \mathrm{min}$ insulin infusion. Note that the scales are identical

lines between the percent muscle in forearm and blood flow were significantly different between the insulin concentrations. Statistically significant differences could be demonstrated between baseline and step II ( $2 \mathrm{mU} / \mathrm{kg} \cdot \mathrm{min}$ insulin infusion rate, $p<0.05)$, between baseline and step III $(5 \mathrm{mU} / \mathrm{kg} \cdot \mathrm{min}$, $p<0.001)$ and between steps I $(1 \mathrm{mU} / \mathrm{kg} \cdot \mathrm{min})$ and III $(p<0.05)$. Furthermore, the insulin-induced increment in forearm blood flow was positively correlated with the percent muscle in forearm at all insulin concentrations (step I $r=0.58$; step II $r=0.56$; step III $r=0.73, p<0.05$ for each).

Sequential insulin dose-response study with measurement of forearm glucose uptake and blood flow (plethysmography) and leg blood flow (plethysmography)

In eight subjects forearm and calf blood flow were measured simultaneously using venous occlusion plethysmography during sequential insulin infusions. 
T. Utriainen et al.: Insulin regulation of limb blood flow

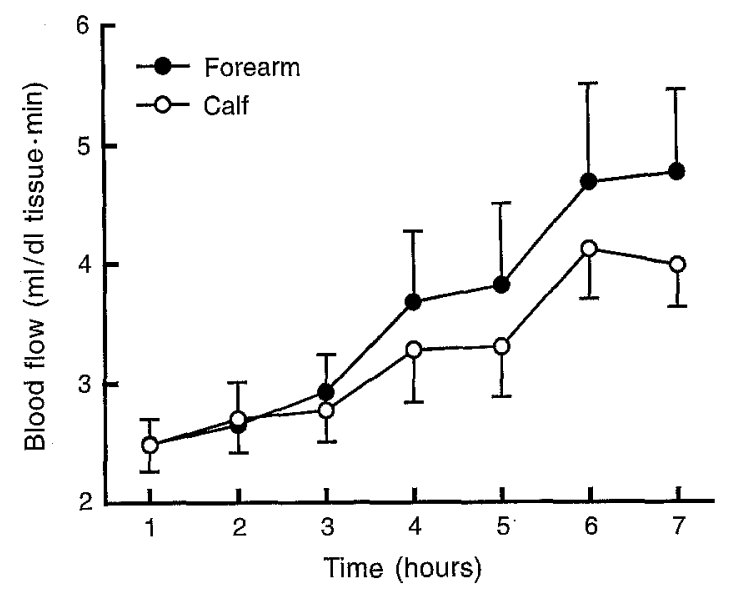

Fig. 6. Comparison of forearm and calf blood flow measured using venous occlusion plethysmography during a sequential hyperinsulinaemic clamp in a group of normal volunteers $(n=8)$

Serum insulin concentrations averaged $5 \pm 1,64 \pm 2$, $136 \pm 5$ and $484 \pm 16 \mathrm{mU} / 1$ basally and at steps I, II and III, respectively. Blood flow increased similarly and dose-dependently in both the forearm and the calf and averaged $2.5 \pm 0.2,2.8 \pm 0.3(p<0.01$ vs basal), $3.7 \pm 0.6(p<0.05$ vs basal and $p=0.08$ vs ste$\mathrm{p} \mathrm{I})$ and $4.7 \pm 0.7 \mathrm{ml} / \mathrm{dl}$ tissue $\mathrm{min}(p<0.01 \mathrm{vs}$ basal and $p<0.05$ vs steps I and II) in forearm, and $2.5 \pm 0.2,2.7 \pm 0.3$ (NS vs basal), $3.3 \pm 0.4$ ( $p<0.05$ vs basal and step I) and $4.0 \pm 0.4 \mathrm{ml} / \mathrm{dl}$ tissue $\mathrm{min}$ ( $p<0.001$ vs basal, $p<0.01$ vs step I and $p<0.05$ vs step II) in calf, basally and at steps I, II and III, respectively (Fig. 6). The blood flow rates in forearm and calf did not significantly differ basally or at any hyperinsulinaemic level. Forearm and calf blood flow were closely correlated both basally $(r=0.80$, $p<0.02)$ and during insulin stimulation $(r=0.73$ $0.88, p<0.05-0.01)$. In these subjects the glucose infusion rate averaged $36.6 \pm 4.2,65.9 \pm 6.6(p<0.001$ vs step I) and $83.3 \pm 6.7 \mu \mathrm{mol} / \mathrm{kg} \cdot \min (p<0.001$ vs steps I and II), and glucose arteriovenous difference $1.73 \pm 0.22,1.87 \pm 0.22$ and $1.90 \pm 0.13 \mathrm{mmol} / 1$ (all differences NS) at steps I, II and III, respectively.

\section{Discussion}

The purpose of the present study was to clarify some of the controversies regarding the blood flow response to insulin. By performing sequential clamps in which insulin concentrations 60,140 and 460 $480 \mathrm{mU} / 1$ were achieved, we found that the maximal glucose arteriovenous difference across the forearm was achieved at the lowest, high physiological insulin concentration. In contrast, both forearm and calf blood flow, when determined simultaneously with plethysmography, increased similarly and maximally by $60-90 \%$ in response to increasing doses of insulin
(Fig.6). The maximal increase in blood flow by insulin in the leg was only $27 \%$ when measured with Doppler ultrasound. Furthermore, the percent of muscle in forearm was found to be a highly significant determinant of both basal blood flow and its response to insulin.

Although forearm blood flow has been measured in numerous studies, few data are available regarding the reproducibility of such measurements. Also, the possible impact of the method used to calibrate various plethysmographs has seldom been characterized. These issues are worth a thorough analysis because of the controversial results regarding insulin stimulation of blood flow. In the present study, the reproducibility of the strain-gauge plethysmographic technique during a 7-h control study averaged $13 \%$ which was slightly less than the mean increase in blood flow at the lowest insulin concentration $(17 \%)$. When analysed individually, however, the blood flow responses to insulin at the lowest insulin concentration varied from $-12 \%$ to $+60 \%$ even in a homogenous group of young normal weight volunteers. Thus, the failure to observe a significant increase in blood flow in some $[8,9,11-14]$ but not in other studies $[16,17]$ at an insulin concentration of approximately $100 \mathrm{mU} / 1$ could at least partly be explained by methodological factors as well as by interindividual variation.

Several techniques can be used to calibrate a plethysmograph (Fig.1). If the slope approach is used, blood flow is measured only in the segment underlying the strain gauge. With the withdrawal method, total forearm flow (except for hand blood flow) is more likely to be measured. However, as the distribution of vascular resistances may vary between different segments of the forearm, even this method largely reflects flow in the segment circumscribed by the gauge. In the present study, forearm blood flow was approximately $20 \%$ lower with the withdrawal than with the slope method. The most likely explanation for this difference is that the widest segment of the forearm where the strain gauge was placed contains the highest proportion of muscle [9] and the slope method reflects flow exclusively in this segment.

We tested the Doppler ultrasound as a technique to non-invasively determine leg blood flow. In a recent study employing a 3 -h insulin infusion which increased the plasma insulin concentration to approximately $5000 \mathrm{mU} / 1$, Buchanan et al. [33] failed to observe any increase in leg blood flow. In fact, to our knowledge, increased limb blood flow in response to insulin has not previously been observed using this method. Instead of the conventional time-averaged flow velocity measurement, we used the systolic peak blood flow velocity as an indicator of blood flow changes because of its easier technical applicability, and because it was assumed to reflect possible changes in average flow velocity. Maximally, only a 
$10 \%$ increase in peak flow velocity was observed which did, however, exceed the methodological variation of $4 \%$. Even after taking the increase in heart rate into consideration, the maximum increase in femoral blood flow was $27 \%$. This was less than half of the $63 \%$ increase in calf blood flow detected with plethysmography. As the insulin responses in the forearm and the calf measured with plethysmography were similar and as the plethysmography data resembles those obtained in a comparable group of normal volunteers using the thermodilution technique across the leg [2-3], we feel that peak flow velocity, even when multiplied with heart rate, cannot be used to estimate changes in leg blood flow. Whether this is because peak flow velocity does not reflect average flow velocity, or because the femoral vessel diameter changes in response to insulin, remains unresolved.

In the present study, forearm blood flow rose continuously during the sequential insulin infusion steps. At the lowest, high physiological insulin concentration $(61 \mathrm{mU} / \mathrm{l})$, the mean increase was $17 \%$. At the following two supraphysiological insulin concentrations, the increases in blood flow averaged 50 and $113 \%$. In contrast, the glucose arteriovenous difference reached its maximum at the end of the first insulin dose and remained constant thereafter. These data could be interpreted to suggest that insulin regulation of glucose extraction is of key importance within the physiological range of insulin concentrations, whereas insulin effects on blood flow can then play only a minor role. The latter interpretation differs somewhat from that of Laakso et al. [2] who observed a $60-70 \%$ increase in leg blood flow at an insulin concentration of $100 \mathrm{mU} / 1$ (insulin infusion rate $1 \mathrm{mU} /$ $\mathrm{kg} \cdot \mathrm{min}$ ) in normal volunteers comparable to those in the present study. In the latter study, however, the first blood flow measurements were made $1.5 \mathrm{~h}$ after starting the $1 \mathrm{mU} / \mathrm{kg} \cdot \mathrm{min}$ insulin infusion, and this insulin infusion had already been preceded by a 3-h insulin infusion at a rate of $0.25 \mathrm{mU} / \mathrm{kg} \cdot \mathrm{min}$, and a $2-\mathrm{h}$ insulin infusion at a rate of $0.5 \mathrm{mU} / \mathrm{kg} \cdot \mathrm{min}$. In view of the similar increases in forearm and calf blood flow in the present study, and the modest increases in forearm blood flow in short studies employing separate insulin infusions, it is likely that the magnitude of the blood flow response to insulin is not so much dependent upon whether blood flow is measured across the forearm or the leg as it is on the concentration and duration of insulin infusion. In keeping with this, Lundgren et al. [34] found a $39 \%$ increase in calf blood flow at $2 \mathrm{~h}$ and a $91 \%$ increase at $6 \mathrm{~h}$ during a $1.7 \mathrm{mU} / \mathrm{kg} \cdot \mathrm{min}$ insulin infusion.

Forearm blood flow was directly correlated with the percent forearm muscle both basally and during hyperinsulinaemia (Fig.5). We estimated forearm muscle content from biceps skinfold thickness using the equation of Maughan et al. [30]. This equation is based on the relationship between forearm muscle content as measured from computerised tomography scans and biceps skinfold thicknesses in a group of normal volunteers (age 25 years, height $170 \mathrm{~cm}$, weight $65 \mathrm{~kg}$ ) closely resembling the present group. A more reliable estimate of forearm muscle content could have been obtained by its direct measurement by e. g. computerised tomography scanning. The relationship between basal flow and the percent muscle might suggest that blood flow through muscle tissue is the quantitatively most important contributor to basal blood flow. The correlation between resting forearm blood flow and maximal oxygen uptake [14] could also be explained by a higher percent muscle in forearms of athletes. Recently, Elia and Kurpad [35] suggested that skin blood flow accounts for $34 \%$ of the resting forearm blood flow although the skin accounts for only $8.5 \%$ of forearm volume. Muscle tissue contributed by $49 \%$ to flow and by $65 \%$ to forearm volume. The data from the present study would suggest that although a significant fraction of flow may still be through the skin in the basal state [35], insulin selectively increases muscle blood flow. First, even if the reproducibility of the laser Doppler method for measuring skin blood flow was poor (CV $50 \%$ ), there was no tendency for skin perfusion to change. Since total forearm flow increased by more than $100 \%$, unchanged skin blood flow indicates that the major change occurred outside the skin. Second, our recent results where leg muscle blood flow has been directly visualized and quantitated using radiowater and positron emission tomography, have indicated that blood flow through muscle is by far the most important contributor to resting blood flow, and that insulin increases limb blood flow specifically in muscle tissue [36]. Finally, we found that the slope of the regression line characterizing the relationship between the percent muscle in forearm and total forearm blood flow increased significantly as a function of the insulin concentration (Fig.5). The intercepts on the $y$-axis were not significantly different (data not shown) indicating that when forearm muscle mass is zero, there is no increase in blood flow. These data not only further support the idea that insulin increases blood flow in muscle tissue but also indicate that forearm composition is a major factor which explains the interindividual variability of the flow response to insulin. A greater insulin effect on blood flow might therefore contribute to the greater whole body insulin sensitivity which characterizes weight lifters and long-distance runners [22]. The possibility that an increased forearm muscle capillary density or other histological or biochemical features were responsible for the correlation between relative forearm muscle content and blood flow was not addressed in the present study.

We conclude that physiological hyperinsulinaemia increases glucose uptake predominantly by stimulat- 
ing glucose extraction while supraphysiological concentrations increase forearm glucose uptake by increasing blood flow. It should be emphasized, that the blood flow response appears to be dependent both on time and insulin concentration and that the sequential study design may overestimate the contribution of blood flow to glucose uptake. However, the increase in blood flow is similar in the forearm and the calf when determined with plethysmography, and its magnitude closely resembles that obtained with the thermodilution technique indicating that there are no inherent differences between the blood flow responses of forearm and leg tissues to insulin. A major fraction of the variability of basal forearm blood flow and its response to insulin is explained by interindividual differences in forearm composition.

Acknowledgements. We thank Ms. S. Hämäläinen for excellent technical assistance, Ms. S. Aarnio for drawing the figures and the volunteers for their help. HY is supported by grants from the Finnish Academy of Science.

\section{References}

1. Zierler KL (1961) Theory of the use of arteriovenous concentration differences for measuring metabolism in steady and non-steady states. J Clin Invest 40: 2111-2125

2. Laakso M, Edelman SV, Brechtel G, Baron AD (1990) Decreased effect of insulin to stimulate skeletal muscle blood flow in obese man. J Clin Invest 85: 1844-1852

3. Baron AD, Brechtel-Hook G, Johnson A, Hardin D (1993) Skeletal muscle blood flow. A possible link between insulin resistance and blood pressure. Hypertension 21: 129-135

4. Baron AD, Laakso M, Brechtel G, Edelman SV (1991) Mechanism of insulin resistance in insulin-dependent diabetes mellitus: A major role for reduced skeletal muscle blood flow. J Clin Endocrinol Metab 73: 637-643

5. Laakso M, Edelman SV, Brechtel G, Baron AD (1992) Impaired insulin mediated skeletal muscle blood flow in patients with NIDDM. Diabetes 41: 1076-1083

6. Baron AD, Steinberg H, Brechtel G, Johnson A (1994) Skeletal muscle blood flow independently modulates insulin-mediated glucose uptake. Am J Phys 266: E248-E253

7. Baron AD, Brechtel G (1993) Insulin differentially regulates systemic and skeletal muscle vascular resistance. Am J Physiol 265: E61-E67

8. Jackson RA, Hamling JB, Blix PM et al. (1986) The influence of graded hyperglycemia with and without physiological hyperinsulinemia on forearm glucose uptake and other metabolic responses in man. J Clin Endocrinol Metab 63: 594-604

9. Yki-Järvinen H, Young AA, Lamkin C, Foley JE (1987) Kinetics of glucose disposal in whole body and across the forearm in man. J Clin Invest 79: 1713-1719

10. Kelley DE, Reilly JP, Veneman T, Mandarino LJ (1990) Effects of insulin on skeletal muscle storage, oxidation, and glycolysis in humans. Am J Physiol 258: E923-E929

11. Yki-Järvinen H, Sahlin K, Ren JM, Koivisto VA (1990) Localization of rate-limiting defect for glucose disposal in skeletal muscle of insulin-resistant type I diabetic patients. Diabetes 39: 157-167

12. Capaldo B, Napoli R, Di Bonito P, Albano G, Sacca L (1991) Dual mechanism of insulin action on human skele- tal muscle: identification of an indirect component not mediated by FFA. Am J Physiol 260: E389-E394

13. Bonadonna RC, Prato SD, Saccomani MP et al. (1993) Transmembrane glucose transport in skeletal muscle of patients with non-insulin-dependent diabetes. J Clin Invest 92: $486-494$

14. Ebeling P, Bourey R, Koranyi L et al. (1993) Mechanism of enhanced insulin sensitivity in athletes. Increased blood flow, muscle glucose transport protein (GLUT-4) concentration, and glycogen synthase activity. J Clin Invest 92: 1623-1631

15. Bennet WM, Connacher AA, Scrimgeour CM, Jung RT, Rennie MJ (1990) Euglycemic hyperinsulinemia augments amino acid uptake by human leg tissues during hyperaminoacidemia. Am J Physiol 259: E185-E194

16. Anderson EA, Hoffmann RP, Balon TW, Sinkey CA, Mark AL (1991) Hyperinsulinemia produces both sympathetic neural activation and vasodilatation in normal humans. $\mathrm{J}$ Clin Invest 87: 2246-2252

17. Bonadonna RC, Saccomani MP, Seely L et al. (1993) Glucose transport in human skeletal muscle. The in vivo response to insulin. Diabetes 42: 191-198

18. Vollenweider P, Tappy L, Randin D et al. (1993) Differential effects of hyperinsulinemia and carbohydrate metabolism on sympathetic nerve activity and muscle blood flow in humans. J Clin Invest 92: 147-154

19. Gallen IW, MacDonald IA (1990) Effects of blood glucose concentration on thermogenesis and glucose disposal during hyperinsulinemia. Clin Sci 79: 279-285

20. Dela F, Mikines KJ, von Linstow M, Secher NH, Galbo H (1992) Effect of training on insulin-mediated glucose uptake in human muscle. Am J Phys 263: E1134-E1143

21. Richter EA, Mikines KJ, Galbo H, Kiens B (1989) Effect of exercise on insulin action in human skeletal muscle. J Appl Physiol 66: 876-885

22. Yki-Järvinen H, Koivisto VA (1983) Effects of body composition on insulin sensitivity. Diabetes 32: 965-969

23. DeFronzo RA, Tobin JD, Andres R (1979) Glucose clamp technique: a method for quantifying insulin secretion and resistance. Am J Physiol 237: E214-E223

24. Rizza RA, Mandarino LJ, Gerich JE (1981) Dose-response characteristics for effects of insulin on production and utilization of glucose in man. Am J Physiol 240: E630-E639

25. DeFronzo RA, Ferrannini E, Hendler R, Felig P, Wahren J (1983) Regulation of splanchnic and peripheral glucose uptake by insulin and hyperglycemia in man. Diabetes 32: 3545

26. Yki-Järvinen $\mathbf{H}$, Consoli A, Nurjhan N, Young AA, Gerich JE (1989) Mechanism for underestimation of isotopically determined glucose disposal. Diabetes 38: 744-751

27. Dillon RS (1965) Importance of hematocrit in interpretation of blood sugar. Diabetes 14: 672-674

28. Clarke RSJ, Hellon RF (1957) Venous collection in forearm and hand measured by the strain-gauge and volume plethysmograph. Clin Sci 16: 103-117

29. Gill RW (1985) Measurement of blood flow by ultrasound: accuracy and sources of error. Ultrasound Med Biol 11: 625-641

30. Maughan RJ, Watson JS, Weir J (1984) The relative proportions of fat, muscle and bone in the normal human forearm as determined by computed tomography. Clin Sci 66: 683689

31. Kadish AH, Little RL, Sternberg JC (1968) A new and rapid method for the determination of glucose by measurement of rate of oxygen consumption. Clin Chem 14:116-131

32. Desbuquois B, Aurbach DG (1971) Use of polyethylene glycol to separate free and antibody-bound peptide hor- 
mones in radioimmunoassays. J Clin Endocrinol Metab 33: 732-738

33. Buchanan TA, Thawani H, Kades W et al. (1993) Angiotensin $I I$ increases glucose utilization during acute hyperinsulinemia via a hemodynamic mechanism. J Clin Invest 92: $720-726$

34. Lundgren F, Edén E, Arfvidsson B, Lundholm K (1991) Insulin time-dependent effects on the leg exchange of glucose and amino acids in man. Eur J Clin Inv 21: 421-429
35. Elia M, Kurpad A (1993) What is the blood flow to resting human muscle? Clin Sci 84: 559-563

36. Nuutila P, Ruotsalainen U, Sipilä H et al. (1994) Simultaneous quantitation of insulin induced increases in glucose uptake and blood flow in skeletal muscle using ${ }^{15} \mathrm{O}$-water, ${ }^{18} \mathrm{FDG}$ and PET. Diabetes 43 [Suppl 1]: 72A, (Abstract) 